\title{
Araştırma Makalesi / Research Article \\ Atmosferdeki Partikül Madde (PM10) Miktarındaki Değişimin GNSS ile Kestirilen Islak Zenit Gecikmesi Üzerindeki Etkisinin Araştırılması
}

\author{
Gökhan GÜRBÜZ ${ }^{1 *}$, Kurtuluş Serdar GÖRMÜŞ ${ }^{1}$, Umut ALTAN ${ }^{1}$ \\ ${ }^{1}$ Zonguldak Bülent Ecevit Üniversitesi, Mühendislik Fakültesi, Geomatik Mühendisliği Bölümü, Zonguldak. \\ Sorumlu yazar* e-posta: gokhan.gurbuz@beun.edu.tr ORCID ID: https://orcid.org/0000-0001-5491-4623 \\ ksgormus@beun.edu.tr \\ ORCID ID: https://orcid.org/0000-0002-7910-2071 \\ umutaltann@gmail.com \\ ORCID ID: https://orcid.org/0000-0001-9323-3652 \\ Geliş Tarihi: 18.03.2020 Kabul Tarihi: 16.06 .2020 \\ Öz \\ Anahtar kelimeler \\ GNSS; \\ Islak Zenit Gecikmesi; \\ $\mathrm{PM}_{10}$ \\ Zonguldak \\ Hava kirliliği, insan sağlığını ve yaşadığımız çevreyi tehdit etmesinin yanı sıra bulunduğu yerde görüş \\ mesafesini de düşürmektedir. Bunun sebebi, atmosferin alt katmanı olarak bilinen troposferde kirliliğe \\ sebep olan gazların ve partikül maddelerin, ışığı saçması ve emmesidir. Troposferdeki gazlar, su buharı \\ miktarı ve diğer meteorolojik parametreler, 1214-1610 megahertz aralığındaki mikrodalga sinyaller \\ kullanarak konum belirleyen Global Uydu Navigasyon Sistemi'nde (GNSS), troposferik zenit gecikmesi \\ olarak adlandırılan bir gecikmeye sebep olmaktadır. Hava kirliliği seviyesini ölçmeye yarayan \\ değişkenlerden biri olan ve 10 mikrometreden küçük, 2.5 mikrometreden büyük çapa sahip Partikül \\ Madde (Particulate Matter - $\mathrm{PM}_{10}$ ) miktarlarındaki ve yoğunluğundaki değişimlerin de GNSS \\ sinyallerinde gecikmeye sebep olduğu düşünülmektedir. Bu çalışmanın temel amacı, hava kirliliği ölçme \\ parametrelerinden $\mathrm{PM}_{10}$ değerlerinin GNSS sinyallerindeki troposferik gecikmeye olan etkisinin \\ araştırılmasıdır. Bu amaçla, Türkiye'nin partikül yoğunluğu olarak en yoğun şehirlerinden biri olan \\ Zonguldak ili seçilmiştir. Zonguldak ili Merkez ilçesinde bulunan ve devamlı ölçüm yapan Türkiye Ulusal \\ Sabit GNSS Ağı (TUSAGA-Aktif) istasyonlarından "ZONG" GNSS istasyonundan elde edilen veriler, GIPSY- \\ OASIS II yazılımı ile değerlendirilmiştir. Birbirini takip eden ve aynı meteorolojik koşullar altında benzer \\ ve farklı PM 10 miktarına sahip günlere ait Islak Zenit Gecikmeleri (ZWD) incelenerek GNSS sinyallerine \\ etkileri araştırılmıştır. Çalışma sonucunda, $\mathrm{PM}_{10}$ değerinin görece yüksek olduğu günlerde ortaya çıkan \\ ZWD farklarının, PM $_{10}$ değerinin görece düşük olduğu günlerde ortaya çıkan ZWD farklarından, fazla \\ olduğu ortaya çıkarken, $\mathrm{PM}_{10}$ değerinin görece yüksek olduğu günlerde ortaya çıkan ZWD farklarına ait \\ lineer bir korelasyon bulunamamıştır.
}

\section{Investigation into the Effect of Atmospheric Particulate Matter (PM 10$)$ Concentrations on GNSS Estimated Zenith Wet Delay}

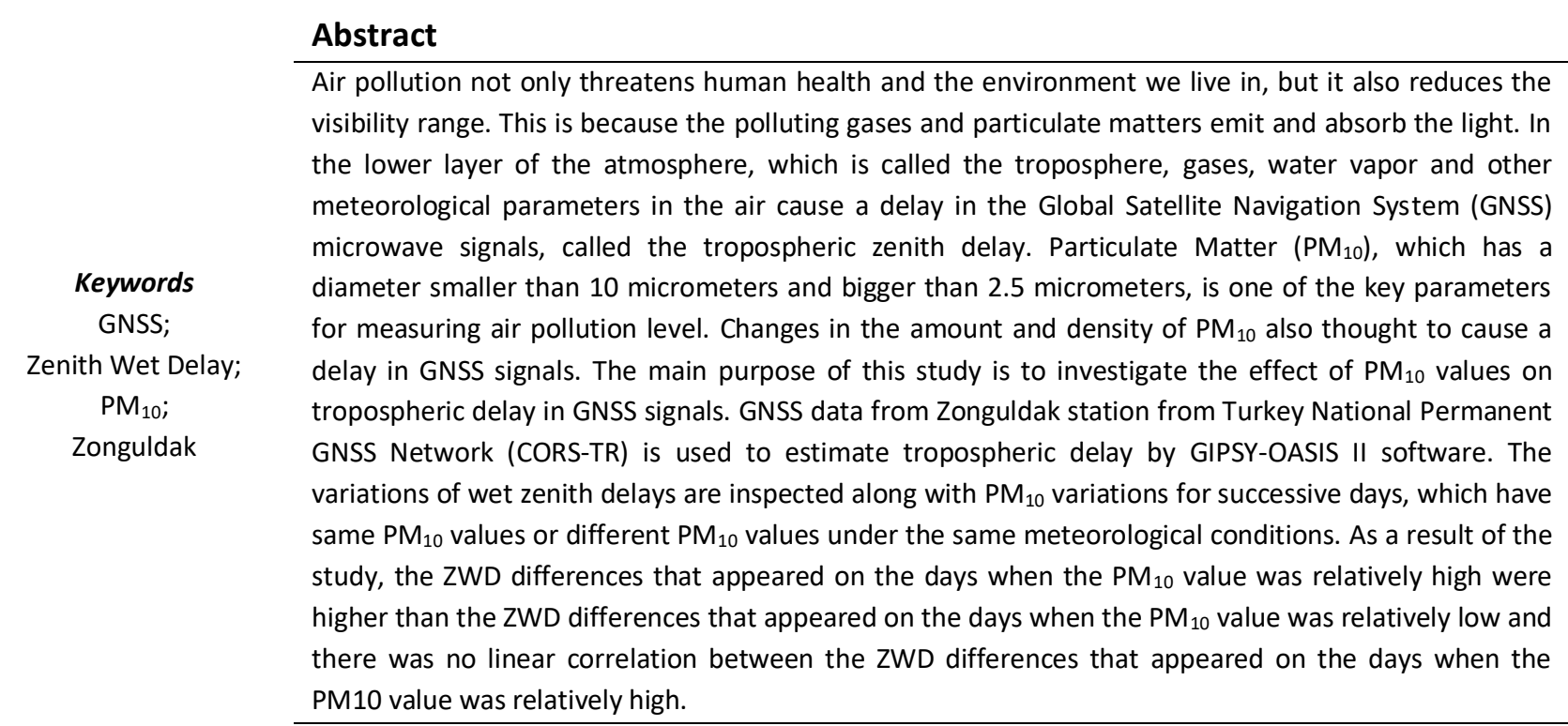




\section{Giriş}

Hava, gazlar (karbondioksit, azot, oksijen vs.), partikül maddeler (toz, polen, tüy vs.) ve su buharı ile atmosferi oluşturan bir gazdır. Atmosferdeki başlıca gazlar \%78,08 azot, \%20,95 oksijen, \%0,93 argon, \%0,03 karbondioksit şeklinde sıralanabilmektedir. Bu gazlar arasında dünya hayatı ve insan için en önemli gaz oksijendir. Kirletici gazların başlı başına havada tamamen bulunması değil, oksijen miktarının azlığı ve diğer gazların oranındaki değişim de hava kirliliği olarak adlandırımalıdır (Tekbaş 2010).

Hava kirliliği, doğal olaylar veya insan kaynaklı olabilir. Örneğin olarak yangınlar atmosferdeki azot miktarının artmasına sebep olur. Insan kaynaklı olarak bakılırsa, herhangi bir sebeple yakılan ateşler, fabrika ve ev bacalarından atmosfere yayılan dumanlar ve araçların egzozları karbon monoksit, kükürt dioksit ve nitrik asit gibi zehirli gazların havaya karışmasına sebep olur. Sonuçta atmosfere salınan gazlar havadaki gaz yoğunluğunu değiştirerek hava kirliliğine neden olmaktadır. Amerika Birleşik Devletleri Çevre Koruma Ajansı standartlarına göre hava kirliliği, atmosferde bulunan ozon $\left(\mathrm{O}_{3}\right)$, karbon monoksit $(\mathrm{CO})$, sülfür dioksit $\left(\mathrm{SO}_{2}\right)$, nitrojen oksit (NO), likitler ve partiküller gibi bileşenlerin miktarlarına göre belirlenir (Robert-Lambach 2010).

Ancak pratikte genellikle kirlilik, havadaki katı parçacıklar ve kükürt dioksit miktarına göre belirlenir. Bu küçük partiküller sigara dumanı, egzoz gazları, orman yangınları, rüzgâr ile taşınan toz, volkanik gazlar ve deniz buharlaşması gibi olaylar sonucu meydana gelen katı ve sıvı bileşenlerin atmosfere karışması ile oluşmaktadır. Çapları 10 $\mu m^{\prime}$ den küçük, $2.5 \mu m^{\prime}$ den büyük partikül maddeler "kaba partiküller" olarak adlandırılır. Daha çok kırma, öğütme işlemleri ve yol tozlarından kaynaklanır. Partikül boyutları çok geniş bir aralığa sahiptir. Toz, duman, is gibi bazı partiküller gözle görülebilecek kadar büyük olmasına rağmen ancak mikroskopla görülebilen boyutlarda partiküller de bulunmaktadır. Çapları
$2.5 \mu \mathrm{m}^{\prime}$ den daha küçük partiküller ise "ince partiküller" olarak adlandırııır (U.S. Environmental Protection Agency 1987, Seinfeld and Pandis 2016). Hava kirliliği, insan, bitki, hayvan yaşamına ve çevre kalitesine zarar veren bir veya daha fazla kirleticinin belirli miktar ve sürelerde atmosferde bulunması olarak tarif edilebilir (Müezzinoğlu 1987). Çizelge 1'de Hava Kalite İndeksi, farklı kirletici unsurların sınır değerleri ile birlikte özetlenmiştir.

Çizelge 1. Hava Kalitesi İndeksi.

\begin{tabular}{|c|c|c|c|}
\hline $\begin{array}{l}\text { Hava Kalitesi } \\
\text { İndeksi }\end{array}$ & $\begin{array}{c}\mathrm{SO}_{2} \\
{\left[\mu \mathrm{g} / \mathrm{m}^{3}\right]} \\
1 \text { Saatlik } \\
\text { Ortalama }\end{array}$ & $\begin{array}{c}\mathrm{NO}_{2} \\
{\left[\mu \mathrm{g} / \mathrm{m}^{3}\right]} \\
24 \text { Saatlik } \\
\text { Ortalama }\end{array}$ & $\begin{array}{c}\mathrm{PM}_{10} \\
{\left[\mu \mathrm{g} / \mathrm{m}^{3}\right]} \\
24 \text { Saatlik } \\
\text { Ortalama }\end{array}$ \\
\hline Çok İyi & $0-50$ & $0-45$ & $0-55$ \\
\hline İyi & 51-199 & $46-89$ & $56-109$ \\
\hline Yeterli & $200-399$ & $90-179$ & $110-159$ \\
\hline Orta & $400-899$ & $180-299$ & $160-219$ \\
\hline Kötü & $900-1499$ & $300-699$ & $220-799$ \\
\hline Cok Kötü & $>1500$ & $>700$ & $>800$ \\
\hline
\end{tabular}

Partikül maddelerin yol açtığı hava kirliliğinin, başta insan sağlığı olmak üzere görüş mesafesi, materyaller, bitkiler ve hayvan sağlığı üzerinde olumsuz etkileri vardır. Katı yakıtlar ve akaryakıt gibi karbonlu maddelerin tam yanmamasından meydana gelen katı ve sıvı parçacıkların bir gaz karışımı olan duman, hava kirliliğinin bir çeşitlidir ve görüş uzaklığını azaltıcı bir etkiye sahiptir. Ayrıca, sanatsal ve mimari yapılar üzerinde tahrip edici ve bozucu etkisi vardır. Bitkiler üzerinde ise öldürücü ve büyümelerini engelleyici olabilmektedir. Bu nedenle hava kirliliği hem canlıların sağlığı açısından, hem de ekonomik yönden zarar vericidir (Çevre ve Şehircilik Bakanlığı 2013). Tüm bu negatif etkilere ek olarak partikül maddelerin sinyallere de etkisinin olduğu düşünülmektedir. Partikül maddeler atmosfer katmanının yeryüzüne yakın olan troposfer katmanında bulunmaktadır.

Troposfer, kuru hava ve su buharı karışımından oluşmaktadır. Kuru hava, atmosferdeki gaz yoğunluğuna, gaz dağıımındaki değişimlere bağlı olup, GNSS sinyallerindeki toplam atmosferik gecikmenin (ZTD) yaklaşık \%90'ını oluşturmaktadır. Kuru havada bulunan gaz karışımı ideal gaz davranışı sebebiyle sebep olduğu hidrostatik 
gecikme miktarı (ZHD) yüksek doğrulukla belirlenebilmektedir (Saastamoinen 1972). Hidrostatik gecikme, ölçü noktasında ölçülen basınç, sıcaklık ve nem ile zenit doğrultusunda \%2 hata ile modellenebilmektedir. Islak zenit gecikmesinin modellenmesi, su buharının yere ve zamana göre hızla değişim göstermesi nedeniyle hidrostatik gecikmeye kıyasla çok daha zordur.

Uydu ile alıcı arasında iletilen sinyalin yükseklik (eğim) açısı $15^{\circ}$ nin altında olduğu durumlarda troposferik gecikme çok büyük boyutlara ulaşmakta ve modellemesi daha da zorlaşmaktadır. Bunun sebebi ise yükseklik (eğim) açısı $15^{\circ}$ 'nin altında olduğu durumlarda sinyalin troposferde daha uzun yol kat etmesidir. Troposferik gecikmenin zenit açısındaki değeri (uydunun yükseklik açısındaki değerine eşlenmemiş durumu, kısaca sinyalin başucu doğrultusundaki gecikme değeri) 2,2 m civarındadır. Yükseklik açısının $0^{\circ}$ ye yakın olduğu durumlarda toplam zenit gecikmesi $25 \mathrm{~m}$ ile $85 \mathrm{~m}$ arasındadır (Özlüdemir 2004). Troposferik gecikmeyi kestirmek amacıyla pek çok standart troposfer model kullanılmaktadır (Hopfield 1971, Saastamoinen 1972). Troposferik gecikme miktarları farklı akademik yazılımlar ve bu yazılımlara entegre edilmiş troposferik modeller aracılı̆ı ile kestirilebilmektedir. Bu modeller Dünya çapında uzun süreli meteorolojik gözlemler sonucu elde edilmiş ve doğrulukları birçok akademik çalışma ile kanıtlanmıştır. Ancak bu konudaki temel sorun troposferin ya da bütün olarak atmosferin doğasının tam olarak anlaşılamamış olmasıdır. Bu sebeple uzun süreli meteorolojik gözlemlerden yararlanılarak, matematiksel bağıntılar olan yüzey modelleri geliştirilmiştir.

$\mathrm{PM}_{10}$ miktarının GNSS ile yapılan uygulamalardaki etkisinin araştırılması hakkında çok sınırlı sayıda yayın bulunmaktadır. Kasım 2014 ve Aralık 2015'e ait veriler üzerinde yapılan bir çalışma da $\mathrm{PM}_{10}$ ve $\mathrm{PM}_{2.5}$ 'in GNSS sinyalleri üzerindeki etkisi araştırımış ve etkilerin gürültü olarak sayılabilecek kadar küçük olduğu görülmüştür (Lau and He 2017).

\section{Materyal ve Metot}

Batı Karadeniz bölgesinde Zonguldak il sınırları içerisinde yer alan Merkez ilçesi çalışma alanı olarak belirlenmiştir. Bölgenin arazi yapısı, Karadeniz Bölgesi genelinde olduğu gibi dik ve eğimlidir. Şehir merkezi, deniz seviyesinde olup ve tepelerle çevrelenmektedir. Bu bölgede endüstriyel ve insanların sebep olduğu gaz salınımı sebebiyle açığa çıkan gazlar, çökmeye uğrayarak gerek meteorolojik koşullar gerekse topografik olarak şehir merkezinin etrafını çevreleyen tepelerden dolayı, şehir merkezinde toplanmaktadır. Çalışma alanında insanların sebep olduğu gaz salınımının ana nedeni özellikle kış aylarında bölgede yakıt kaynağı olarak taşkömürünün kullanılmasıdır. 2015 yılından itibaren Merkez ilçenin çoğu mahallesinde doğalgaz kullanımına başlanılsa dahi, hala doğalgaz kullanımına geçmemiş yerleşim yerlerinden dolayı hava kirliliği miktarı kademeli olarak azalsa da tam olarak standart değerlere indirgenmemiştir. Temiz havada bile gazların ışığı saçma özelliğinden (Rayleigh saçılması) dolayı görüş mesafesi birkaç kilometre ile sınırlıdır. Havanın kirli olması durumunda, gazlar ve partiküllerin ışığı saçma ve emilimi nedeniyle görüş mesafesi azalmaktadır (Zeydan 2014).

Zonguldak il merkezinde 2013-2106 yılları arası ölçülen ortalama, minimum, maksimum $\mathrm{PM}_{10}$ konsantrasyonları, Şekil 1'de gösterilmiştir. Çevre ve Şehircilik Bakanlığına ait Zonguldak Hava Kalitesi İzleme İstasyonu'ndan elde edilen verilerle, ilgili yılların $\mathrm{PM}_{10}$ ölçümlerine ait zaman serisi grafikleri, günlük ortalamalar kullanılarak oluşturulmuştur (Şekil 2). Çizelge 1 'de verilen Hava Kalite Indeksi açısından kritik değerler de işlenmiştir. $\mathrm{PM}_{10}$ verilerindeki dalgalanmanın oluşmasının sebebi özellikle kış aylarında ısınma amaçlı yoğun kömür tüketimidir. Yaz aylarında kömür tüketimi olmaması $\mathrm{PM}_{10}$ değerlerindeki azalmayı göstermektedir. 


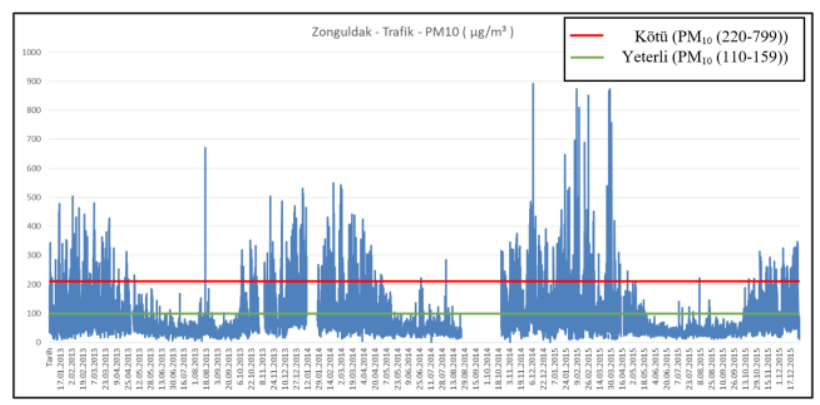

Şekil 1. Zonguldak Merkez ilçesi $\mathrm{PM}_{10}$ zaman serisi.

Bu çalışmada GNSS verisi olarak TUSAGA-Aktif ağına dahil ZONG istasyonuna ait veriler kullanılmıştır. ZONG istasyonu, hava kalitesi ölçüm istasyonu ve meteorolojik sensörlere çok yakın olduğundan dolayı özellikle seçilmiştir. Buna ek olarak Islak zenit gecikmesi değerlerinin karşılaştırılması için Meteoroloji Genel Müdürlüğü'nden sıcaklık, basınç, nem ve yağış miktarı verileri temin edilmiştir. Çalışmanın bu kısmında Jet Propulsion Laboratory (JPL) bilim insanları tarafından geliştirilen GIPSY-OASIS ॥ (Webb 1995) yazılımı kullanılarak GNSS verilerinin değerlendirilmesi yapılmış ve ıslak troposferik gecikmeler hesaplanmıştır. GIPSY-OASIS II çiftli fark yöntemini kullanmayıp, bunun yerine saat parametreleri, jeodezik parametreler ile birlikte kestirilmektedir ve fark yöntemleri uygulanmadan taşıyıcı faz ve pseudorange verileri aynı anda işlenmektedir. (Blewitt 1998). Saat parametreleri, stokastik olarak kestirilirken ve yığınlar arasında öncül korelasyon olmamaktadır. Troposferik zenit gecikmesi, atmosferik türbülansın beklenen fiziği ile yakından ilişkili olan rasgele yürüyüş modeli tarafından stokastik olarak (yani, her epokta bir zamanla değişen bir parametre olarak) tahmin edilmektedir (Linkwitz and Hangleiter 2012). Çizelge 2'de GIPSY-OASIS II yazılımı değerlendirme stratejisi özetlenmiştir.

Çizelge 2. GIPSY-OASIS II ile yapılan değerlendirmeler de kullanılan parametreler.

\begin{tabular}{cc}
\hline Parametre & Tercih Edilen Değerler \\
\hline Uygulama Yöntemi & Hassas Konumlama \\
\hline Zenit Gecikmesi Kestirim Aralığı & 1 Saat \\
\hline Zenit Kısıtlaması & 0,50 \\
\hline Yükseklik Eğim Açısı & 10 Derece \\
\hline Yörünge Bilgisi & JPL Hassas \\
\hline İyonosfer Çözümü & İyonosferden Bağımsız \\
\hline Kuru ve Islak İzdüşüm Fonksiyonu & VMF1 \\
\hline
\end{tabular}

Çizelge 2'deki uygulama yöntemi, değerlendirmede kullanılacak çözüm stratejisi, zenit kısıtlaması değerlendirme sonucu elde edilecek zenit gecikmesi miktarlarına uygulanacak zorlama miktarını göstermektedir. Belirtilen zorlama miktarı metre cinsinden olup, zenit gecikmesi hesabında oluşabilecek kaba hataları gidermek için kullanılmaktadır. Ek olarak çalışmada iyonosferik gecikmenin giderilmesi için iyonosferden bağımsız çözüm uygulanmıştır.

\section{Bulgular}

Çalışmada ZONG istasyonuna ait iki yıllık gözlem verileri GIPSY-OASIS II yazılımı kullanılarak değerlendirilmiştir. Sonuç ürün olarak koordinat bilgileri ve zenit gecikmeleri elde edilmiştir. Meteorolojik parametreleri minimum değişkenliğe uğrayan fakat $\mathrm{PM}_{10}$ miktarlarındaki değişimin büyük olduğu günlere çizelge 4'te bazı örnekler verilmiştir. Bu günlere ait ıslak zenit gecikmeleri incelerek $\mathrm{PM}_{10}$ miktarının etkisi araştırımıştır. 2015 senesi sonrası, çalışma alanı olan Zonguldak'ta $\mathrm{PM}_{10}$ miktarlarını etkileyen kömür kullanımı kademeli olarak azaldığı için çalışmada 2014 ve 2015 yıllarına ait veriler kullanılmıştır. Belirtilen tarihlerin Kasım, Aralık, Ocak ve Şubat aylarından oluşmasının sebebi ise kış aylarında kömür tüketiminin yoğun olmasıdır.

Çalışmada seçilen günlerin birbirine yakın olmasının sebebi ise yaklaşık olarak aynı meteorolojik parametrelere sahip fakat farklı $\mathrm{PM}_{10}$ değerlerine sahip günlerdeki ZWD değerlerinin incelenmesi amaçlanmıştır. Çizelge 3'te belirtilen günler birbirini takip eden ve aynı meteorolojik koşullara sahip olan günlere örnek teşkil ederken, kullanılan değerler gün içerisindeki ortalama değerlerdir. Sıcaklık, basınç ve nem gibi meteorolojik parametrelerin değişimleri, ZHD bileşeni hesabı ve modellenmesi için kullanılmaktadır.

Çizelge 3. Belirlenen günlere ait ortalama meteorolojik parametreler.

\begin{tabular}{cccccc}
\hline Zaman & $\begin{array}{c}\text { Sıcaklık } \\
\left({ }^{\circ} \mathbf{C}\right)\end{array}$ & $\begin{array}{c}\text { Basınç } \\
(\mathbf{h P a})\end{array}$ & $\begin{array}{c}\text { Nem } \\
(\mathbf{\%})\end{array}$ & $\begin{array}{c}\text { Yağış } \\
(\mathbf{m m})\end{array}$ & $\begin{array}{c}\mathbf{P M}_{10} \\
{\left[\mu \mathrm{g} / \mathbf{m}^{3}\right]}\end{array}$ \\
\hline $15 / 01 / 2015$ & 5.3 & 1002.26 & 88 & 0.0 & 182.5 \\
\cline { 2 - 6 } $16 / 01 / 2015$ & 5.3 & 1009.24 & 81.2 & 0.0 & 124.2 \\
\hline $06 / 02 / 2014$ & 3.5 & 1004.30 & 85.8 & 0.0 & 133.6 \\
\cline { 2 - 6 } $07 / 02 / 2014$ & 3.5 & 1004 & 84.4 & 0.0 & 160.9 \\
\hline
\end{tabular}




\begin{tabular}{cccccc}
\hline $05 / 12 / 2015$ & 6.8 & 1017.32 & 66.0 & 0.0 & 94.0 \\
\cline { 2 - 6 } $07 / 12 / 2015$ & 5.2 & 1020.05 & 66.8 & 0.4 & 146.7 \\
\hline $19 / 12 / 2015$ & 5.5 & 1015.67 & 85.5 & 0.0 & 117.9 \\
\cline { 2 - 6 } $21 / 12 / 2015$ & 4.9 & 1010.88 & 73.0 & 0.0 & 147.4 \\
\hline $22 / 11 / 2015$ & 19.4 & 994.53 & 39.7 & 0.0 & 57.0 \\
\cline { 2 - 6 } $23 / 11 / 2015$ & 20.0 & 1004.98 & 33.0 & 0.0 & 99.1 \\
\hline $11 / 11 / 2015$ & 15.0 & 1009.35 & 79.5 & 0.1 & 82.3 \\
\cline { 2 - 6 } $12 / 11 / 2015$ & 13.8 & 1002.94 & 76.3 & 0.2 & 120.7 \\
\hline $03 / 11 / 2014$ & 9.7 & 1006.63 & 90.9 & 0.0 & 69.6 \\
$04 / 11 / 2014$ & 9.2 & 1011.09 & 89.0 & 0.0 & 106.6 \\
\hline $29 / 10 / 2014$ & 14.7 & 999.03 & 80.7 & 0.0 & 51.4 \\
\cline { 2 - 6 } $30 / 10 / 2014$ & 14.6 & 1003.15 & 79.7 & 0.0 & 80.2 \\
\hline
\end{tabular}

Belirtilen günler detaylıca incelendiğinde 05-07 Aralık 2015 tarihinde ortalama $\mathrm{PM}_{10}$ miktarında 50 $\mu \mathrm{g} / \mathrm{m}^{3}$ lük bir fark görülürken, ZONG istasyonunun GNSS verisinden hesaplanan Islak zenit gecikmesi değerlerinde günlük ortalama $30 \mathrm{~mm}$ 'lik bir fark belirlenmiştir. Şekil 3'te düşey eksen metre cinsinden Islak zenit gecikmesini, yatay eksen günün saatini belirtmektedir.
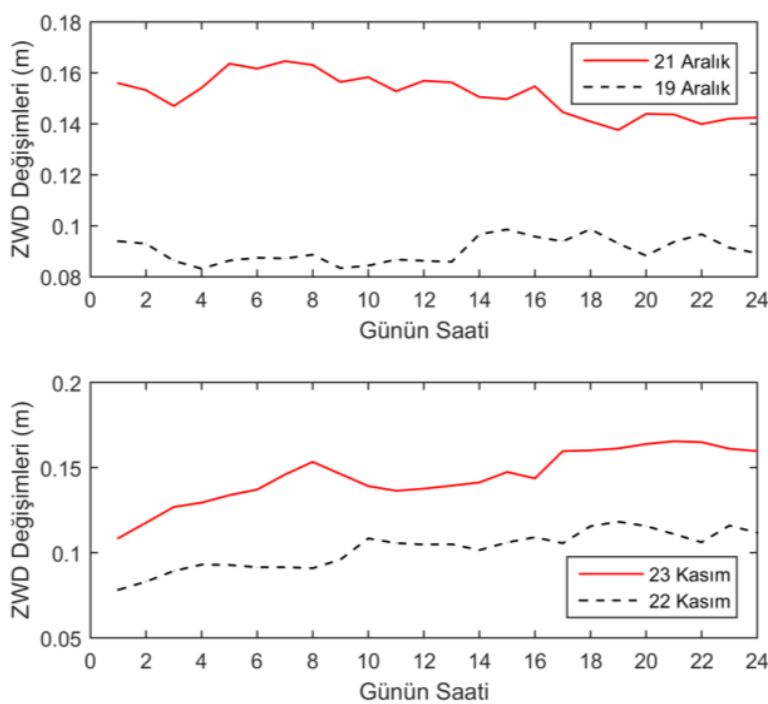

Şekil 3. 19-21 Aralık 2015 ve 21-22 Kasım 2015 tarihlerine ait ıslak zenit gecikmesi değerleri.

Çizelge 3'te verilen diğer günlere ait ortalama $\mathrm{PM}_{10}$ farkları ve sonuç olarak elde edilen ortalama ZWD farkları Çizelge 4'te verilmiştir. Bu örneklere ek olarak aynı meteorolojik koşullara ve $\mathrm{PM}_{10}$ miktarlarına sahip günler de incelenmiştir. Farklı aylardan seçilen örnekler irdelendiğinde özellikle 1 ile $10 \mu \mathrm{g} / \mathrm{m}^{3}$ lük $\mathrm{PM}_{10}$ farklılığına sahip olan günler seçilmiştir.

Çizelge 4. Belirlenen günlere ait $\mathrm{PM}_{10}$ ve $Z W D$ farkları.

\begin{tabular}{|c|c|c|c|}
\hline Zaman & $\begin{array}{c}\text { PM }_{10} \text { Ort. } \\
{\left[\mu \mathrm{g} / \mathrm{m}^{3}\right]}\end{array}$ & $\begin{array}{c}\text { PM }_{10} \text { Farkları. } \\
{\left[\mu \mathrm{g} / \mathrm{m}^{3}\right]}\end{array}$ & $\begin{array}{c}\text { ZWD Farkları. } \\
{[\mathrm{mm}]}\end{array}$ \\
\hline $15 / 01 / 2015$ & 182.5 & \multirow{2}{*}{58.3} & \multirow{2}{*}{20} \\
\hline $16 / 01 / 2015$ & 124.2 & & \\
\hline $06 / 02 / 2014$ & 133.6 & \multirow{2}{*}{27.3} & \multirow{2}{*}{10} \\
\hline $07 / 02 / 2014$ & 160.9 & & \\
\hline $05 / 12 / 2015$ & 94.0 & \multirow{2}{*}{52.7} & \multirow{2}{*}{30} \\
\hline $07 / 12 / 2015$ & 146.7 & & \\
\hline
\end{tabular}

\begin{tabular}{|c|c|c|c|}
\hline $19 / 12 / 2015$ & 117.9 & \multirow{2}{*}{29.5} & \multirow{2}{*}{50} \\
\hline $21 / 12 / 2015$ & 147.4 & & \\
\hline $22 / 11 / 2015$ & 57.0 & \multirow{2}{*}{42.1} & \multirow{2}{*}{40} \\
\hline $23 / 11 / 2015$ & 99.1 & & \\
\hline $11 / 11 / 2015$ & 82.3 & \multirow{2}{*}{38.4} & \multirow{2}{*}{20} \\
\hline $12 / 11 / 2015$ & 120.7 & & \\
\hline $03 / 11 / 2014$ & 69.6 & \multirow[t]{2}{*}{37} & \multirow[t]{2}{*}{10} \\
\hline $04 / 11 / 2014$ & 106.6 & & \\
\hline 29/10/2014 & 51.4 & \multirow{2}{*}{28.8} & \multirow{2}{*}{30} \\
\hline $30 / 10 / 2014$ & 80.2 & & \\
\hline
\end{tabular}

Şekil 3'te aynı meteorolojik koşullarda farklı PM10 değerlerine ait günlerin değerlendirildiği grafikler görülmektedir. $\mathrm{PM}_{10}$ değeri değişimine bağlı olarak bulunan ZWD farklarının anlamlı olup olmadığının görülmesi için $\mathrm{PM}_{10}$ değeri eşdeğer olarak kabul edilen (Değişim<10 $\mu \mathrm{g} / \mathrm{m}^{3}$ ) günlerde ZWD değişimleri incelenmiştir. Çizelge 5 'te aynı meteorolojik koşullarda ve görece aynı $\mathrm{PM}_{10}$ değerlerine sahip günlerin ZWD değerleri incelenmiştir.

Çizelge 5. Belirlenen günlere ait ortalama meteorolojik parametreler.

\begin{tabular}{cccccc}
\hline Zaman & $\begin{array}{c}\text { Sıcaklık } \\
\text { (oC) }\end{array}$ & $\begin{array}{c}\text { Basınç } \\
\text { (hPa) }\end{array}$ & $\begin{array}{c}\text { Nem } \\
(\%)\end{array}$ & $\begin{array}{c}\text { Yağış } \\
(\mathbf{m m})\end{array}$ & $\begin{array}{c}\mathbf{P M}_{10} \text { Ort. } \\
{\left[\mu \mathrm{g} / \mathbf{m}^{3}\right]}\end{array}$ \\
\hline $15 / 12 / 2015$ & 7.5 & 1011.7 & 79 & 0.0 & 101.2 \\
\cline { 2 - 6 } $16 / 12 / 2015$ & 5.3 & 1011.1 & 83.5 & 0.0 & 104.2 \\
\hline $06 / 11 / 2015$ & 11.8 & 1006 & 90.4 & 0.0 & 82 \\
\cline { 2 - 6 } $07 / 11 / 2015$ & 12.1 & 1008.6 & 95.7 & 0.0 & 84 \\
\hline $08 / 02 / 2015$ & 3.9 & 991 & 81.6 & 0.0 & 61 \\
\cline { 2 - 6 } $09 / 02 / 2015$ & 3 & 991.4 & 78 & 0.0 & 66 \\
\hline
\end{tabular}

Çizelge 5 'de belirtilen günler birbirini takip eden ve aynı meteorolojik koşullara sahip olan günlere örnek teşkil etmektedir. Belirtilen günler detaylıca incelendiğinde 15-16 Aralık 2015 tarihinde ortalama $\mathrm{PM}_{10}$ miktarında $3 \mathrm{\mu g} / \mathrm{m}^{3 ` l u ̈ k ~ b i r ~ f a r k ~}$ görülürken, ZONG istasyonunun GNSS verisinden hesaplanan Islak zenit gecikmesi değerlerinde günlük ortalama $4 \mathrm{~mm}$ 'lik bir fark belirlenmiştir (Şekil 4). 

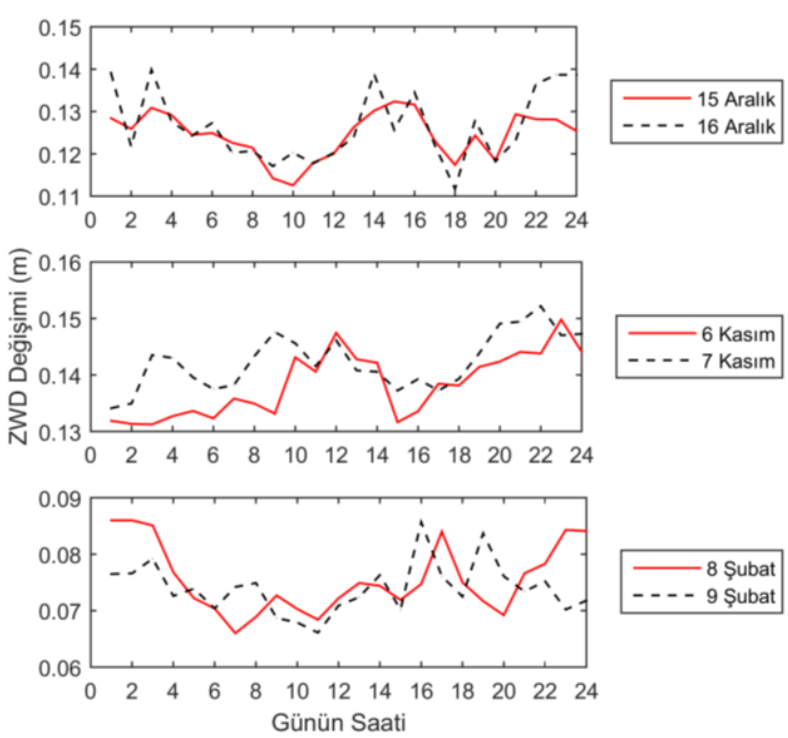

-8 Şubat ---9 Şubat

Şekil 4. 15-16 Aralık 2015, 6-7 Kasım 2015 ve 8-9 Şubat 2015 tarihlerine ait Islak zenit gecikmesi değerleri.

Çizelge 5'te verilen diğer günlere ait ortalama $\mathrm{PM}_{10}$ farkları ve sonuç olarak elde edilen ortalama ZWD farkları Çizelge 6 'te verilmiştir.

Çizelge 6. Belirlenen günlere ait $\mathrm{PM}_{10}$ ve $Z W D$ farkları.

\begin{tabular}{cccc}
\hline Zaman & $\begin{array}{c}\mathbf{P M}_{10} \text { Ort. } \\
{\left[\mu \mathrm{g} / \mathrm{m}^{3}\right]}\end{array}$ & $\begin{array}{c}\mathbf{P M}_{10} \text { Farkları. } \\
{\left[\mu \mathrm{gg} / \mathrm{m}^{3}\right]}\end{array}$ & $\begin{array}{c}\text { ZWD Farkları. } \\
{[\mathrm{mm}]}\end{array}$ \\
\hline $15 / 12 / 2015$ & 101.2 & 3 & 3 \\
\cline { 2 - 2 } $16 / 12 / 2015$ & 104.2 & 3 & 4 \\
\hline $06 / 11 / 2015$ & 82 & 2 & 2 \\
$07 / 11 / 2015$ & 84 & 2 & 2 \\
\hline $08 / 02 / 2015$ & 61 & 5 & 2 \\
\hline $09 / 02 / 2015$ & 66 & & \\
\hline
\end{tabular}

\section{Tartışma ve Sonuç}

Çalışma kapsamında Zonguldak ili Merkez ilçesinde bulunan ZONG GNSS istasyonu 2014-2015 yıllarına ait verilerinin değerlendirilmesi sonucu ıslak zenit gecikme değerleri elde edilmiştir. Yapılan değerlendirmeler sonucunda şehir merkezinde bulunan hava kalitesi ölçüm istasyonu verilerinden elde edilen $\mathrm{PM}_{10}$ değerleri, ZWD değerlerinin değişimleri ile birlikte irdelenmiştir. İncelemeler sonucu eş meteorolojik koşullara sahip birbirini takip eden günlerden $\mathrm{PM}_{10}$ değerinin yüksek ve düşük olduğu günlere ait sonuçlar verilmiştir. Bu günlere ait saatlik ZWD değerleri, genel $\mathrm{PM}_{10}$ değişimleri ile karşılaştırıldığında gün içerisinde özellikle öğlen saatleri (11:00-13:00) ve akşam (18:00-21:00) saatlerinde değişime uğradığı görülmektedir. Bu farkın sebebi ise Zonguldak kent merkezinde kalorifer kazanlarının öğlen ve akşam saatlerinde günde iki kere kömür ile beslenmesi ve belirtilen saatlerde araç trafiği miktarının artışı gösterilebilir.

Eş meteorolojik koşullara ve farklı $\mathrm{PM}_{10}$ değerlerine sahip günlerdeki genel ZWD farklılığı ise Çizelge 4'te de görüldüğü gibi gün içerisindeki $\mathrm{PM}_{10}$ değişimine bağı olarak 20-50 mm aralığında değişime uğramıştır. Birbirine çok yakın $\mathrm{PM}_{10}$ değerlerine sahip günlerdeki genel ZWD farklılı̆̆ da Çizelge 6 'da görüldüğü gibi gün içerisindeki değişimine bağlı olarak 2-4 $\mathrm{mm}$ aralığında değişime uğramaktadır. Bu iki karşılaştırmadan elde edilen sonuç, $\mathrm{PM}_{10}$ değerinin görece yüksek olduğu günlerde ortaya çıkan ıslak zenit gecikmesi farklarının, $\mathrm{PM}_{10}$ değerinin görece düşük olduğu günlerde ortaya çıkan ıslak zenit gecikmesi farklarına kıyasla daha fazla olduğudur. Ancak, çalışma kapsamında yapılan analizlerde, aynı meteorolojik koşullara sahip ve birbirini takip eden günlere ait $\mathrm{PM}_{10}$ miktarındaki değişim ile $\mathrm{ZWD}$ farkları arasında incelenen günler için lineer bir korelasyon bulunamamıştır. Bu durum geçmiş çalışmalarda da belirtildiği gibi $\mathrm{PM}_{10}$ un GNSS uygulamaları üzerine tanımlanmış standart bir model olmamasının da sebebi olarak görülmektedir (Lau and He 2017). Ancak bu tip çalışmalar yapılarak gerek istasyon sayısının gerek ise değerlendirme için kullanılan verinin zaman aralığının arttırılması ile gelecekte bir model oluşturulması için adımlar atılması öngörülebilir. Ek olarak yapılan bu çalışma, eş meteorolojik koşulların kullanılması ile $\mathrm{PM}_{10}$ değerinin ZWD üzerindeki etkisinin araştırılması konusunda özgündür ve geliştirilmeye açıktır.

Çalışma alanındaki ıslak zenit gecikmesi ve dolayısı ile toplam zenit gecikmesi miktarlarında belirlenen bu farklılıklara ek olarak $\mathrm{PM}_{10}$ miktarındaki yüksek değişimlerin konum bilgisine olan etkisinin araştırılması da konum doğruluğu çalışmalarına katkıda bulunacaktır. Ancak düşük seviyedeki $\mathrm{PM}_{10}$ ortalamasına sahip çalışma alanlarında, $\mathrm{PM}_{10}$ miktarının GNSS sinyallerine olan etkisi göz ardı edilebileceği bu çalışmanın önemli sayılabilecek bir sonucudur. Günümüz koşullarında, ısınma amacıyla 
doğalgaz kullanımına kademeli olarak geçiliyor olsa da, özellikle enerji üretimi kaynaklı kömür tüketimi, $\mathrm{PM}_{10}$ değerlerinin artmasına yol açmaktadır. $\mathrm{PM}_{10}$ miktarındaki bu artışın, insan sağlığı ve görüş mesafesi üzerindeki etkilerine ek olarak hassas konumlama ve GNSS tabanlı diğer çalışmalara etkisi de yok sayılmamalıdır. Gelecekte jeodezik amaçı yapılacak çalışmalarda, çalışma alanında ya da çalışma alanına yakın bölgelerdeki $\mathrm{PM}_{10}$ değerlerinin elde edilmesi ve özellikle yüksek $\mathrm{PM}_{10}$ miktarına sahip bölgelerde, $\mathrm{PM}_{10}$ miktarının sebep olacağı sinyal gecikmelerinin göz ardı edilmemesi önerilmektedir. Gelecekte, çalışma kapsamında kullanılan GNSS istasyon sayısının ve değerlendirme için kullanılacak veri aralığının arttırılması, aynı zamanda diğer hava kirliliği unsurlarının da göz önünde bulundurulması planlanmaktadır.

\section{Kaynaklar}

Blewitt, G., 1989. Carrier phase ambiguity resolution for the Global Positioning System applied to geodetic baselines up to $2000 \mathrm{~km}$. Journal of Geophysical Research: Solid Earth, 94(B8), 10187-10203.

Gurbuz, G., Jin, S. G., Mekik, C., 2015. Sensing precipitable water vapour (PWV) using GPS in Turkey: validation and variations. Satellite Positioning: Methods, Models and Applications, InTech-Publisher, Rijeka, Croatia, 117-129.

Hopfield, H. S., 1971. Tropospheric effect on electromagnetically measured range: Prediction from surface weather data. Radio Science, 6(3), 357367.

Lau, L., He, J., 2017. Investigation into the effect of atmospheric particulate matter (PM2. 5 and PM10) concentrations on GPS signals. Sensors, 17(3), 508.

Linkwitz, K., Hangleiter, U., 2012. High precision navigation: integration of navigational and geodetic methods. Springer Science \& Business Media, Germany, 647.

Müezzinoğlu, A., 1987. Hava Kirliliğinin ve Kontrolünün Esasları, Dokuz Eylül Üniversitesi, Yayınları, İzmir, 165-167.
Özlüdemir, M. T., 2004. The Stochastic Modelling of GPS Observations. Turkish Journal of Engineering and Environmental Sciences, 28, 223- 231.

Saastamoinen, J., 1972. Atmospheric correction for the troposphere and stratosphere in radio ranging satellites. The use of artificial satellites for geodesy, 15, 247-251.

Seinfeld, J. H., Pandis, S. N., 2016. Atmospheric chemistry and physics, from air pollution to climate change. $2^{\text {nd }}$ edition, John Wiley and Sons Inc., U.S.A, ISBN: 0-471-82857-2, 1120.

Tekbaş, Ö. F., 2010. Çevre Sağlığı. Gülhane Askeri Tıp Akademisi Basım Evi. Ankara. 5, 143, 156.

U.S. Environmental Protection Agency, 1987. Indoor Air Quality Implementation Plan, Appendix A, USA.

Webb, F., Zumberge J., 1995. An introduction to Gipsy/Oasis II, Rep. JPLM D-11088, Jet Propulsion. Lab., Pasadena, California, U.S.A.

Zeydan, Ö., 2014. Zonguldak Bölgesi $\mathrm{PM}_{10}$ Konsantrasyon Dağııımının Modellenmesi, Doktora Tezi, Kocaeli Üniversitesi Fen Bilimleri Enstitüsü, Kocaeli, 184. 